\title{
As póleis do Ocidente grego à luz da Arqueologia Clássica: uma entrevista com Maria Beatriz B. Florenzano*
}

\author{
The 'póleis' of the Greek West in the light of Classical \\ Archaeology: an interview with Maria Beatriz B. Florenzano
}

M

aria Beatriz B. Florenzano é professora titular de Arqueologia Clássica do Museu de Arqueologia e Etnologia da Universidade de São Paulo e doutora em Ciência Social (Antropologia Social) pela mesma universidade, tendo realizado estágios de pós-doutorado no Center for Old World Archaeology and Art da Brown University, Estados Unidos; no Ashmolean Museum, Oxford, Inglaterra; e na Université Catholique de Louvain, Bélgica. É coordenadora geral do Laboratório de Estudos sobre a Cidade Antiga (Labeca) ${ }^{1}$ e bolsista produtividade 1-C do CNPq. Em suas investigações, dedicase ao estudo dos modelos de organização do espaço na Grécia antiga. É autora de um vasto repertório bibliográfico voltado, em especial, para o estudo da ocupação grega no ocidente mediterrâneo. No âmbito de seus trabalhos junto ao Labeca, vem organizando importantes coletâneas, dentre as quais podemos citar Estudos sobre a cidade antiga (2009) e Khoríon - Xopíon: cidade e território na Grécia antiga (2019), a mais recente, às quais devemos acrescentar outras tantas contribuições sob a forma de artigos científicos, livros e capítulos de livros. As investigações conduzidas pela autora permitem que avancemos na compreensão da forma como os gregos, em especial aqueles das póleis, se apropriaram dos espaços urbano e rural, a maneira como os constituíram e transformaram segundo suas necessidades e interesses.

1. Martinho Guilherme Fonseca Soares: Professora, já faz algum tempo que falamos do diálogo entre História e Arqueologia, uma das bandeiras dos pesquisadores reunidos em torno da Escola dos Annales. Desse modo, para abrir essa entrevista, gostaríamos de ouvi-la sobre esse assunto.

\footnotetext{
* Entrevista concedida a Martinho Guilherme Fonseca Soares em 15 de maio de 2020.

${ }^{1}$ O Labeca é vinculado ao Museu de Arqueologia e Etnologia da Universidade de São Paulo. Para consultar sua página, acesse: <http://labeca.mae.usp.br>.
} 
Maria Beatriz B. Florenzano: Inicialmente, quero agradecer a oportunidade dessa entrevista. No ponto em que me encontro da carreira universitária, uma entrevista como esta propicia a reflexão em torno de um balanço do que foi feito e do que ainda pode ser realizado na nossa área.

Mas, passando à sua pergunta. Eu sou do tempo em que - ao menos aqui no Brasil - aprendíamos que a História era uma disciplina "mãe" e era "auxiliada" por vários outros campos do saber, como a Arqueologia, a Numismática, a Paleografia, a Heráldica, a Paleontologia, a Filatelia. Era uma divisão fundada no tipo de fonte primária a ser empregada para o conhecimento do passado e essas áreas "auxiliares" da História eram, supostamente, técnicas, especializadas em disponibilizar informação para a interpretação do historiador. Nesta postura, vinha embutida a hierarquização da fonte primária: o guia para a compreensão do funcionamento das sociedades grega e romana era o texto. O objeto, o artefato, devia ilustrar o texto. As perguntas sobre essas sociedades eram formuladas por esses textos. Naturalmente porque, àquele momento, o tipo de conhecimento que se buscava tinha um viés específico: a política, os acontecimentos, a grande arte, a interpretação feita pelos antigos a respeito de sua sociedade. A partir dos anos 1970 e 1980, no que diz respeito à História Antiga, é que se começa a reconhecer a importância do papel desempenhado pelo documento material na compreensão das sociedades mediterrâneas, porque também o foco da História começa a mudar: ganha importância a vida cotidiana das pessoas, a relação entre gêneros, a relação entre pobres e ricos, o contato entre grupos diferentes, as formas de subsistência, a religiosidade, a construção da memória e das identidades e tantos outros aspectos das sociedades. E o principal desta tendência - como nos ensina o grande arqueólogo inglês, Anthony Snodgrass (1987) - é que os textos estão preparados a responder certo tipo de pergunta e estas mesmas perguntas nunca poderão ser respondidas pelos objetos. Estes, por sua vez, colocam outras perguntas cujas respostas somente o seu estudo sistemático pode responder. Hoje, é preciso dizer que mais e mais os historiadores têm sido compelidos a aceitar o papel fundamental da Arqueologia como disciplina independente para o conhecimento das sociedades antigas e que esse conhecimento não se constrói apenas com os textos.

2. Ao dedicarmos esse dossiê ao estudo da expansão grega no Mediterrâneo, somos conduzidos, de imediato, a investigar as possíveis conexões entre as 'póleis' da Grécia continental e insular e aquelas que, a partir do século VIII a.C., passaram a ser fundadas a leste e a oeste do Mediterrâneo. Sabemos que um elemento importante de conexão entre 
as 'póleis' eram os cultos. Nesse sentido, como a Arqueologia pode contribuir para o estudo das modalidades de devoção dos gregos que se estabeleceram nas 'apoikiai'?

R.: Com relação à religiosidade dos gregos no Ocidente mediterrânico, eu entendo que temos que partir de duas premissas básicas: 1) no século VIII a.C., em que se presencia o estabelecimento das apoikiai no Ocidente mediterrânico, a pólis como estrutura organizacional da sociedade grega estava ainda em formação; as apoikiai do Ocidente trazem uma contribuição a essa formação; 2) a religiosidade desses gregos possuía várias camadas: a religião oficial de cada pólis que vai se configurando muito aos poucos, os ritos domésticos, o culto em grandes santuários, a devoção particular de cada um, e assim por diante. Deve-se lembrar também como a religiosidade era parte integrante do desenho das identidades políades, da pólis como um todo ou de grupos específicos no interior de cada uma delas. Ora pois, os grupos de gregos que chegavam ao Ocidente a partir do século VIII vinham de várias partes da Grécia do Leste. Muitas fundações contaram com a participação de grupos mistos, que tinham divindades diferentes como patronas. No Ocidente, foi necessário proceder a uma acomodação do ponto de vista religioso entre os vários grupos de gregos. Mas também foi necessária uma acomodação, no aspecto religioso, com a nova situação que esses gregos passaram a enfrentar: contato com populações diversificadas na Itália do Sul, na Sicília, no sul da França; topografia, vegetação, clima, recursos hídricos diferentes daqueles presentes na área original de proveniência dos gregos. Todos estes fatores entraram em combinação na escolha de divindades principais e secundárias, na valorização de aspectos da geografia para a criação de cultos e ritos (divinização de rios e de fontes de água, por exemplo), valorização das divindades da agricultura (cultos de Deméter e Perséfone na Sićlia, por exemplo) e valorização de divindades que podiam ter também um sentido para as populações locais (como Hera, cultuada em tantas partes e muito em áreas de fronteiras e de contato cultural). Estes gregos das apoikiai estavam construindo uma identidade nova, própria, estavam se afirmando em uma nova região e os deuses entravam com força nessa construção identitária. A Arqueologia tem uma importância fundamental na reconstituição da paisagem religiosa dessas novas fundações no Ocidente: identificação de templos, de altares grandes e pequenos no interior dos espaços domésticos; de pequenos santuários, e de grandes santuários na malha urbana e na hinterlândia; na identificação de terrenos consagrados no interior da malha urbana; na análise de oferendas de póleis ocidentais nos grandes santuários pan-helênicos, como no de Olimpia, onde os gregos afirmavam a sua helenidade; no estudo da paisagem de poder criada por póleis específicas no terreno, por meio de instalação de templos e/ ou santuários de divindades oficiais; pela representação de divindades e ritos em vasos 
pintados ou em moedas. São muitos os suportes materiais em que divindades oficiais registravam sua presença. Lembrar que a religião na Antiguidade impregnava as esferas da sociedade (em maior ou menor grau dependendo da época e localidade) nos ajudará a captar em cada artefato o valor religioso.

3. Sobre as razões políticas e, sobretudo, econômicas que levaram à expansão grega, como a Arqueologia pode iluminar o estudo dessa temática?

R: Saber por que os gregos saíram da Grécia do Leste e a partir do século VIII decidiram instalar-se de modo mais permanente em regiões da Itália do Sul, Sicília, Norte da África, sul da França é uma questão pouco simples. A historiografia desde o século XIX valorizou muito as questões econômicas: falta de terras agriculturáveis nas Ilhas e na Grécia Balcânica. Mas esta é uma visão reducionista que não leva em consideração a diversidade dos grupos que foram em direção ao Ocidente, que não considera os aspectos fundamentais da reestruturação da sociedade no Leste mediterrânico no final da Idade do Ferro e não leva em consideração o fato de que muitos gregos desde a época palacial já conheciam bem o Ocidente, que singravam o Mediterrâneo em companhia dos fenícios, levando e trazendo metais, grãos, cerâmica e tantos outros produtos.

Um certo revisionismo historiográfico neste século XXI tem ressaltado que a chamada "colonização" grega do Ocidente mediterrânico não foi um movimento único e que as fundações de apoikiai teriam ocorrido em largo espaço de tempo sem grandes intencionalidades, como em um processo um tanto aleatório. Mas, na verdade, me parece que esse revisionismo não tem fundamento empírico, pois a Arqueologia mostra desde a segunda metade do século VIII o traçado de malhas urbanas com espaços destinados a rituais de fundação, espaços religiosos, espaços "oficiais", loteamento de terrenos indicando, sim, que este foi um processo em concerto, que conduziu muitas levas de gregos a lugares já antes conhecidos e muitas vezes mapeados em viagens anteriores de reconhecimento. É o famoso caso de Mégara Hibleia, na Sicília, mas também de Siracusa, de Naxos, das cidades de Zancle e de Régio no Estreito entre a Sicília e a Itália do Sul, de Síbaris, de Taras. Mesmo que sejam malhas urbanas não completas, no sentido de não estarem preenchidas, os vestígios de seus traçados com espaços destinados a atividades públicas mostram a intencionalidade da fundação de assentamentos permanentes.

Creio eu que a movimentação de reorganização da sociedade helênica no final da Idade do Ferro na Grécia do Leste criou uma série de conflitos internos de ordem política, de disputa por poder, de disputa por terras, de disputa por rotas comerciais que levou ao planejamento dessa expansão. Cada caso pode ser analisado individualmente sobre 
a prevalência de um ou outro motivo para a organização das expedições fundadoras, mas todos os motivos estão relacionados - no meu entender - a essa reestruturação da sociedade, à configuração da pólis como elemento concatenador dessa reestruturação, ajudada pelo conhecimento que já se tinha do Ocidente e pelo desenvolvimento das técnicas de navegação a partir da Idade do Bronze final.

4. Acerca dos espaços de culto localizados no Ocidente mediterrâneo, como a senhora definiria a importância social dessas estruturas, seu papel em face das diversas funções por elas desempenhadas no contexto das 'póleis'?

R: Como falei acima, os espaços de culto na Magna Grécia (como foi definida a área grega na Itália do sul desde a Antiguidade) e na Sicília tinham um papel fundamental na consolidação da identidade dessas novas fundações. São espaços também de "marcação de território" de uma apoikia diante de outra apoikia e diante da população local (sicânios, elímios na Sicília, e enótrios e seus muitos subgrupos e sículos na Itália do sul). Naturalmente, como dissemos acima, a religiosidade oferecia segurança pessoal e política a esses gregos e os rituais propiciavam a continuidade da vida em lugar diferente, sobretudo para as primeiras gerações de ápoikoi. Mas os santuários de fronteira eram pontos importantes de contato cultural com as populações locais. Como exemplo, podese citar o Santuário na foz do Rio Sele, na apoikia de Poseidonia, na atual região da Campânia, na Itália, que, dedicado a Hera, reforçava o princípio da continuidade da vida, protegendo os partos, os casamentos e assim por diante. Princípio básico que, sem dúvida, também fazia parte das concepções da população local. Outro exemplo interessante é o dos santuários de Deméter e Perséfone na Sicília, divindades totalmente conectadas com a fertilidade da terra e propiciadoras das boas colheitas. Identificadas com a "Grande Mãe", divindade também cultuada entre as populações locais na ilha da Sicília.

5. As publicações do Labeca, mais recentemente, têm dado especial atenção ao estudo da 'khóra', da zona rural, tal como vemos na coletânea de 2019, já mencionada na introdução desta entrevista. Tendo em vista a repartição do espaço políade em uma zona cívica, uma sagrada e uma rural, qual sua opinião sobre a importância da 'khóra' para as 'póleis', em especial para aquelas fundadas no Ocidente mediterrâneo?

R: A pólis na historiografia ocidental foi extremamente valorizada como uma entidade "política". Daí sua definição como cidade-estado. No Labeca, começamos a perceber que a pólis não se define predominantemente por sua forma de governo autônoma em 
relação às outras póleis. Este é um viés que a historiografia, desde a Renascença, adotou por questões específicas do desenvolvimento político europeu. Inclusive, o uso do termo "político" designando os assuntos dos governos é, no nosso entender, incongruente com o que os próprios gregos entendiam por pólis (trata-se de discussão muito longa cujos detalhes são inviáveis de percorrer nos limites desta entrevista). Os estudos de Arqueologia, que mapeiam as instalações da população grega no espaço físico, mostram que falar de "campo e cidade" não funciona para a pólis. A khóra não é só o "campo" que vive em função de um centro urbano para o escoamento de sua produção. A khóra é parte engastada no núcleo urbano, que dela depende não apenas para a produção agrícola, mas dela depende ideologicamente. Não são partes separadas na visão de mundo grega. Aliás, o núcleo urbano, muitas vezes amuralhado, reúne no interior das muralhas tudo que ideologicamente faz sentido para a pólis: casa das pessoas, casa dos deuses, espaço agrícola comum, áreas comuns de reuniões. Todos esses tipos de espaços se reproduzem na khóra de maneira mais dilatada, mas também estão lá presentes. Eu entendo que cada pólis tinha uma proporção variada entre esses vários tipos de espaços, mas a concepção que estava por trás dessas categorias de espaços era sempre a mesma. Muitas vezes pensamos em Atenas com modelo de cidade grega. Na verdade, Atenas era uma exceção. Mesmo assim, dentro das muralhas de Atenas, na Época Clássica, todos os espaços, inclusive o espaço agrícola, vinha representado. Esta constatação pudemos ter a partir do estudo de vários casos, sobretudo na Magna Grécia e na Sicília. Tenho menos conhecimento de casos específicos na Grécia balcânica e nas Ilhas, mas, quero crer e entendo, que esse tipo de constatação possa ser feito também nessa área.

6. François de Polignac (1995), em seu trabalho seminal sobre as origens da 'pólis', avança na interpretação dos santuários extra-urbanos como agentes de distinção espacial em função do impacto que promoviam na percepção da paisagem. ${ }^{2}$ Os santuários são, na definição do autor, marcadores simbólicos, capazes de atuar na defesa do território. A senhora, por sua vez, em 'Definindo a pólis: o papel das fronteiras na integração do espaço políade', texto de 2019, considera a fronteira como uma zona a ser ocupada, que se coloca à frente da comunidade. Nesse sentido, como avalia a proposição de De Polignac acerca do papel dos santuários nas zonas fronteiriças da 'pólis'?

\footnotetext{
${ }^{2}$ Conforme esclarece a professora Maria Beatriz B. Florenzano em seus trabalhos, foi Georges Vallet (1967) que, ao escrever sobre a cidade grega e seu território, introduziu, inicialmente, a temática desses santuários como marcadores territoriais, marcadores de posse e de identidade de uma pólis.
} 
R: Para responder a esta pergunta, tomo a liberdade aqui de voltar ao Projeto Temático do Labeca (2010-2014): "A organização da khóra: a cidade grega diante da sua hinterlândia", que pode ser lido na íntegra em www.labeca.mae.usp.br. Como está lá em nosso projeto (e eu cito): "A hipótese por F. De Polignac (1995) continua sendo discutida nos dias atuais à luz de novos achados arqueológicos". ${ }^{3} \mathrm{Na}$ interpretação de De Polignac, que abrange não apenas a Grécia Ocidental, mas sim toda a helenidade, os santuários extra-urbanos haviam sido fundamentais na própria criação da pólis e em sua história posterior, no sentido de consolidar solidariedades, no sentido de unir os cidadãos em torno de cultos mediados, tanto no território quanto no centro urbano. Divindades protetoras do território e divindades relacionadas à fundação da pólis eram assim cultuadas promovendo a unidade entre as várias partes da cidade. Os santuários entrariam, assim, como elementos importantes na defesa de fronteiras, dando a estas tanto funções estratégicas quanto funções simbólicas. A flexibilidade e as disputas nas fronteiras, seriam apenas mais um motivo para a instalação deste tipo de santuários. Por outro lado, os dados de escavação provindos de cidades como Gela, Taras, Síbaris - para não mencionar apenas o caso bem conhecido da Ática - mostram uma hinterlândia pontuada desde o final do Período Arcaico por um número significativo de locais de culto religioso de muitos tipos, pequenos ou grandes. Fato que pode indicar que o estabelecimento de uma paisagem religiosa implica igualmente no estabelecimento de uma paisagem de poder sem a necessidade de aparato militar. Em muitos casos, esta indicação pode ser reforçada pelo uso da monumentalização de santuários na khóra. Para citar apenas alguns casos, podemos falar das áreas sagradas a leste e oeste da ásty de Selinonte; nos inúmeros santuários extra-urbanos da Ática (que foram inclusive reformados e revitalizados durante o governo de Péricles); nos santuários extra-urbanos de Mileto, de Poseidônia e assim por diante. Então, mesmo que a ocupação territorial de uma pólis não fosse contínua, o domínio de um santuário marcava a sua área de influência, ou a área que pretendia dominar. E isto não apenas no Ocidente grego. Sabe-se, por exemplo, a disputa travada entre as várias póleis da Argólida, no Peloponeso, em torno do santuário de Hera, que em época clássica consolidou-se como o Heraion de Argos, porque foi, afinal, a pólis de Argos que conseguiu o seu controle. No novo projeto do Labeca, em que tratamos de contato cultural, exploro justamente como a cidade de Régio, sentindo-se ameaçada por Lócris, faz-se presente em um santuário de Héracles no meio das montanhas da Calábria, em Castellace, de modo a manifestar

\footnotetext{
${ }^{3}$ Antes de Vallet e desde o início do século XX a ideia predominante era que estes santuários extra-urbanos - ao menos os do Ocidente grego - eram locais de frequentação muito antiga, indígena, que os gregos haviam reforçado quando de sua chegada ao sul da Itália e à Sicília. Em torno dos anos de 1950, começou-se a pensar que talvez tivessem sido locais de frequentação micênica, da Idade do bronze.
} 
a pretensão de domínio ou de influência nessa área (FLORENZANO, 2017). Então, os santuários extra-urbanos, a dispersão de locais de culto pequenos na hinterlândia, fazem parte de uma sistemática de marcação de território por parte das póleis, juntamente com outros elementos como a instalação de postos de observação e de controle de vias, e mesmo de fundação de assentamentos (colônias secundárias como definem os italianos) para marcar até onde uma pólis queria estender o seu domínio. É o caso, por exemplo, da fundação de Casmene por Siracusa na Sicília, assentamento de pico (nas alturas de uma montanha) que controlava a via por onde passavam caravanas dos "inimigos" de Siracusa, e ao mesmo tempo marcava até onde Siracusa, pretendia estender seu domínio territorial (FLORENZANO, 2018). A questão principal, então, é entender que fronteira para os gregos era algo flexível, fluido, e não uma linha contínua, com controle para passaporte.

7. A análise sistemática da malha urbana das 'póleis' do Ocidente grego nos revela que muitas dessas cidades possuíam, desde o momento da sua fundação, padrões topográficos bem definidos, com destaque para a sua ortogonalidade. Dentre as principais estruturas presentes nas zonas ortogonais estava o porto. Gostaríamos que comentasse a relevância das instalações portuárias para as cidades nascentes.

R: Com raríssimas exceções, as cidades fundadas pelos gregos no Ocidente, seja na Magna Grécia, seja na Sicília, seja no sul da França ou no norte da África, eram cidades litorâneas. Algumas dando de frente mesmo para o mar, outras um pouco mais recuadas, por vezes nas alturas, mas com acesso muito fácil para o mar. Elas nos fazem lembrar a frase já muito citada de Platão (109-a-b), no Fédon, sobre como os gregos estavam "instalados à volta do mar tal como formigas e sapos em volta de uma lagoa". Assim, o porto era o canal de saída e de comunicação entre os próprios gregos: desses portos dependiam as várias redes de mobilidade de gregos para todo tipo de atividades (comércio, guerra, contato religioso, mobilidade de tecnologias e conhecimentos e assim por diante). Nesse sentido, a importância do porto era enorme e era o que, de alguma forma, preservava a identidade dos gregos (TACLA et al, 2011). Diga-se de passagem que, em algumas cidades, o porto era a razão de ser, como, por exemplo, o caso das cidades do Estreito de Messina, Zancle (na Sicília) e Régio (na Magna Grécia). Duas fundações calcídicas que controlavam a passagem para o Tirreno dos que vinham do Oriente. Nada disto, porém, significava que as fronteiras terrestres fossem menos importantes. O penetrar na hinterlândia assumiu, sobretudo nas apoikiai do Ocidente, um papel fundamental na conquista de novas terras, no contato cultural, na formatação de novas identidades. 
8. Sobre a relação dos gregos do Ocidente com as populações dos territórios por eles ocupados, o que a Arqueologia teria a dizer sobre os contatos que estabeleceram, em particular sobre a problemática da construção das identidades e alteridades?

R: O tema do contato cultural entre gregos e não gregos no Mediterrâneo é objeto de estudo do atual projeto de pesquisa do Labeca. ${ }^{4}$ Sobre esta temática, a Arqueologia tem contribuído exponencialmente nas últimas três ou quatro décadas. Basta consultar a bibliografia deste projeto para se dar conta do grande volume de textos que tratam dela. ${ }^{5}$ São inúmeros os tipos de documentos materiais e de contextos de achados que nos informam sobre a formação de novas identidades e/ou de permanência de identidades. Mas é sempre imprescindível levar em conta que não temos grupos humanos homogêneos de um e de outro lado que entram em contato. Daí a dificuldade da interpretação e a dependência em análise de contextos amplos de documentos materiais. Seria inviável aqui enumerar todos os tipos de documentos materiais que a Arqueologia nos oferece para o estudo do tema do contato. Posso mencionar neste espaço um ou outro exemplo. Exploram-se com intensidade, por exemplo, as práticas funerárias: desde a forma da deposição do morto até a marcação do enterramento, passando pelo mobiliário funerário. Em Época Arcaica, a incineração era mais comum entre os gregos ou entre as populações itálicas da Magna Grécia? Ou a inumação? Em que porcentagem essas formas de enterramento estão presentes em necrópoles? E o que essas porcentagens nos revelam sobre a mistura de grupos humanos? E quanto às oferendas que faziam parte da tralha que acompanhava o morto? Na Calábria, área que venho examinando ultimamente, em que medida os enterramentos do Alto Arcaísmo trazem como mobiliário funerário a cerâmica de estilo grego ou a de produção local?

Outro exemplo de documento material muito estudado para aferir formas de contato cultural e mudança social é a expansão da organização ortogonal do espaço. Em que medida essa forma organizacional pode revelar a maior ou menor penetração de grupos gregos em áreas precedentemente organizadas de forma esparsa e orgânica? De que modo esse tipo de organização espacial ortogonal e mais centralizada tem a ver com formas de organização do poder? Para falar em um exemplo bem concreto, o que se apresenta no final da Idade do Ferro na Itália do Sul, antes da instalação dos gregos, é uma organização territorial diluída em muitos aldeamentos, com um ou outro assentamento mais denso. A chegada dos gregos parece alterar esse estado de

\footnotetext{
${ }^{4} \mathrm{O}$ título do projeto é Processos de ocupação territorial e de definição de fronteiras: contato cultural no Mediterrâneo grego (sécs. IX -III a.C.), registrado na Fapesp sob o número 2018/09308-1.

${ }^{5}$ Disponível em: <www.labeca.mae.usp.br>
} 
coisas, pois os assentamentos das populações locais vão se centralizando e adensando. Como interpretar esse movimento? O que diz ele a respeito de alterações em formas de governo e de poder, ou da hierarquização social? Abro apenas uma porta para os que se interessarem pela temática.

9. Sabemos que, no que se refere às estimativas demográficas aplicadas ao estudo das sociedades antigas, é preciso sempre agir com cautela. No entanto, é sabido também que a Arqueologia é capaz de revelar, ainda que de modo parcial, os mecanismos de aumento e diminuição populacional. Considerando as necrópoles das 'póleis' fundadas no Ocidente Mediterrâneo, é possível obter alguma inferência sobre o nível de densidade populacional ou sobre as expectativas de vida da população grega?

R:Acredito que as necrópoles se prestem aos estudos demográficos, sem sombra de dúvida. Entretanto, como bem dito na pergunta, a cautela deve permear todo tipo de estudo. Em primeiro lugar, porque dificilmente uma necrópole é explorada em sua totalidade. Devese construir amostragens e projeções estatísticas. Os dados das necrópoles podem ser associados aos dados que se consegue a partir do estudo da extensão da área murada, por exemplo. A análise dos vestígios mortuários dos indivíduos pode também revelar a idade no momento do falecimento, pode revelar doenças, causa da morte, levando assim a conclusões importantes sobre expectativas de vida. Mas, são dados esparsos e de difícil generalização. Com efeito, eu não conheço um estudo geral de demografia que ofereça elementos para saber se na Magna Grécia e na Sicília os gregos viviam mais e em melhor (ou pior) condição do que na Grécia do Leste.

10. À luz da sua experiência como pesquisadora e formadora de recursos humanos em Arqueologia Clássica, como a professora avalia a situação atual da disciplina no País, bem como as tendências futuras, as novas possibilidades de investigação acerca do passado greco-romano?

R: Sobre este assunto, eu sou muito otimista. Sobretudo quando comparo a situação da Arqueologia do Mediterrâneo na década de 1970 quando comecei a estudar na USP e hoje. Atualmente, podemos constatar alunos bem formados, que conseguiram colocação em universidades de qualidade e que vêm formando outros alunos e profissionais; expansão do estudo da Arqueologia no nível do ensino fundamental e médio; integração da Arqueologia do Mediterrâneo com os estudos de História Antiga; projetos internacionais envolvendo grupos de pesquisa no Brasil e em países europeus, no Egito, em Israel e nos Estados 
Unidos; bibliotecas com acervos especializados que servem de suporte a tantos estudos sobre a Antiguidade. Ainda chamo a atenção para tantos laboratórios de pesquisa que reúnem equipes que se aprofundam no estudo de temáticas específicas e que promovem uma interdisciplinaridade saudável entre arqueólogos, historiadores, filósofos, especialistas em literatura e assim por diante. Realmente, acredito que nossa área ganhou muito nas últimas cinco décadas. E esse ganho vem do esforço individual de cada um de nós, em nossas universidades, na insistência em nos mostrarmos diante das agências de fomento/ financiamento, na congregação em torno de associações científicas como, por exemplo, a SBEC e o Grupo de História Antiga da ANPUH, ambas com tantas iniciativas para mostrar como a Arqueologia e a História da Antiguidade têm um papel fundamental na sociedade contemporânea. Destaco ainda o esforço de meus jovens colegas, espalhados pelo Brasil, que vem produzindo material digital/virtual de excelente qualidade, divulgando estudos sobre a Antiguidade. Em tempos de pandemia, recolhidos em casa como estamos neste ano de 2020, esse tipo de material abre um horizonte realmente alvissareiro.

\section{Referências}

FLORENZANO, M. B. B. A organização da khóra na Sicília grega sul-oriental: Siracusa diante de sua hinterlândia (733-598 a.C.). Cadernos do Lepaarq, v. 15, n. 29, p. 247282, 2018.

FLORENZANO, M. B. B. Cidades gregas na Calábria antiga: a configuração dos territórios de Lócris e Régio (sécs. VII-V a.C.). In: CONGRESSO HISTÓRICO INTERNACIONAL AS CIDADES NA HISTÓRIA, II: SOCIEDADE. Atas... Minho: Câmara Municipal de Guimarães, 2017, p. 279-300.

FLORENZANO, M. B. B. Definindo a pólis: o papel das fronteiras na integração do espaço políade. In: FLORENZANO, M. B. B. (Org.). Khoríon - Xopíon: cidade e território na Grécia antiga. São Paulo: Intermeios, 2019, p. 147-160.

PLATÃO. Fedro. São Paulo: Penguin, 2016.

POLIGNAC, F. Cults, territory and the origins of the Greek City-State. London: University of Chicago Press, 1995.

SNODGRASS, A. An Archaeology of Greece. Berkeley: University of California Press, 1987.

TACLA, A. et al. A natureza da cidade portuária e a relação portos-portas em contextos helênicos. In: ALDROVANDI, C. et al. (Org.). Estudos sobre o espaço na Antiguidade. São Paulo: Edusp, 2011, p. 157-194.

VALLET, G. La cité et son territoire. In: CONVEGNO DI STUDI SULLA MAGNA GRECIA, VII. Atti... Nápoles, 1967. 